\title{
Relação entre características morfológicas e produtivas de clones de palma-forrageira ${ }^{1}$
}

\author{
Nalígia Gomes de Miranda e Silva ${ }^{2}$, Mario de Andrade Lira², Mércia Virginia Ferreira \\ dos Santos ${ }^{2}$, José Carlos Batista Dubeux Júnior², Alexandre Carneiro Leão de Mello², \\ Maria da Conceição Silva ${ }^{3}$
}

\footnotetext{
1 Pesquisa financiada pela CAPES e pelo CNPq.

2 Universidade Federal Rural de Pernambuco.

${ }^{3}$ Instituto Agronômico de Pernambuco.
}

RESUMO - Objetivou-se avaliar a relação entre as características morfológicas e produtivas de clones de palma-forrageira para identificação daqueles que contribuem diretamente na produção. Foram avaliados 50 clones de palma-forrageira estabelecidos no palmal há cinco anos e submetidos ao primeiro corte dois anos antes da avaliação. Foram avaliadas as características da planta e do cladódio, e os dados foram analisados pela estatística descritiva, correlação de Pearson e pela análise de trilha das variáveis-independentes explicativas sobre a produção de matéria seca em t/ha/2anos (variável-dependente principal). A produção variou entre clones e foi maior nos clones 8,782 e 418 , cujas produções de matéria seca de 40,8; 18,1 e $12,1 \mathrm{t} \mathrm{MS} / \mathrm{ha} / 2$ anos, respectivamente. Houve baixa correlação entre quase todas as variáveis explicativas e a produção considerada variável principal, por isso, foi necessária a associação de características. As características altura associada à largura da planta explicaram melhor o potencial de produção de matéria seca em $\mathrm{t} / \mathrm{ha} / 2$ anos por apresentarem alta correlação com a produção $(r=0,71)$ e maior efeito direto $(0,69)$. A seleção indireta e não-destrutiva para a produção deve ser baseada em plantas com maior altura e largura.

Palavras-chave: análise de trilha, cactácea, morfologia, produtividade

\section{Relationship between morphological characteristics and productivity of cactus forage clones}

\begin{abstract}
This research evaluated the relationship among the morphological and productive characteristics of clones of cactus forage for identification of those that directly contribute to the production. It was evaluated 50 clones of cactus forage planted five years ago and submitted to the first cut two years before the evaluation. Characteristics of the plant and of the cladode were evaluated and data were analyzed by descriptive characteristics, Pearson correlation and by path analysis of the explanatory independent variables on the dry matter production in $\mathrm{t} / \mathrm{ha} / 2$ years (main dependent variable). Production varied among clones and it was the highest in clones 8,782 e 418 whose dry matter production was of $40.8 ; 18.1$ and 12.1 tMS/ha/2 years, respectively. There was a low correlation among almost all the explanatory variables and the production considered main variable, so, association of characteristics was needed. Characteristic height associated with plant width explained better the potential of dry matter production in $\mathrm{t} / \mathrm{ha} / 2$ years because they presented a high correlation with production $(\mathrm{r}=0.71)$ and the highest direct effect $(0.69)$. Indirect and non destructive selection for production have to be based on higher and larger plants.
\end{abstract}

Keys Words: cactus, morphology, path analyses, productivity

\section{Introdução}

A palma-forrageira Opuntia fícus indica Mill e Nopalea cochenillifera Salm-Dyck conhecida popularmente por palma-gigante e palma-miúda, tem sido largamente utilizada no Nordeste e vem sendo cultivada há várias décadas, por possibilitar a alimentação animal em períodos críticos e ter características morfofisiológicas (metabolismo fotossintético MAC, estômatos distribuídos uniformemente, entre outros), que a tornam tolerante a longas estiagens (Bispo et al., 2007).

Apesar de muito estudada, há poucos relatos dos efeitos diretos e indiretos das características morfológicas da palma-forrageira sobre a produção. Assim, é necessário conhecer os efeitos diretos e indiretos e as correlações entre a produtividade e características morfológicas para 
identificação de características que influenciam a produção. A correlação entre características tem basicamente duas origens: genética e de ambiente. Segundo Falconer (1987), a correlação genética é ocasionada principalmente pelo pleiotropismo (propriedade pela qual um gene condiciona mais de uma característica simultaneamente) e pela ligação gênica (associação não-aleatória entre alelos de diferentes locos), enquanto a correlação fenotípica é definida como a associação entre duas variáveis que podem ser observadas diretamente.

Os coeficientes de correlação permitem ao pesquisador prever, de modo seguro, as alterações em determinada característica provocadas pela pressão de seleção sobre outra característica (Coimbra, 1999). Apesar de a correlação ser uma característica intrínseca a dois caracteres, sua decomposição depende do conjunto de caracteres estudados, que são avaliados pelo conhecimento de sua importância e de possíveis inter-relações expressas em diagrama de trilha (Cruz et al., 2004).

A análise de trilha, que envolve princípios de regressão com variáveis padronizadas é, em essência, um estudo da decomposição do coeficiente de correlação e permite avaliar se a relação entre duas variáveis é de causa e efeito ou determinada pela influência de outras variáveis (Cruz \& Carneiro, 2003).

Considerando-se a importância do estudo das correlações entre as características da planta, realizou-se este trabalho com o objetivo de determinar as características morfológicas que influenciam direta e indiretamente a produtividade de palma-forrageira.

\section{Material e Métodos}

O experimento foi conduzido na Estação Experimental de Caruaru, pertencente ao Instituto Agronômico de Pernambuco (IPA), localizada na cidade de Caruaru, microrregião fisiográfica do agreste de Pernambuco $\left(08^{\circ} 14^{\prime} 18^{\prime \prime}\right.$ de latitude Sul e 35 $55^{\prime} 20^{\prime \prime}$ de longitude Oeste e $537 \mathrm{~m}$ de altitude) no período de julho de 2007 a julho de 2008 . A precipitação pluvial no período experimental (Figura 1) foi em torno de $724 \mathrm{~mm}$ e, desse total, $70 \%$ ocorreram nos meses de março a julho. O clima é classificado como tropical do tipo semiárido, com temperatura média anual de $22,5^{\circ} \mathrm{C}$, oscilando de $25^{\circ} \mathrm{C}$ a $31^{\circ} \mathrm{C}$ na estação seca e de 16 a $20^{\circ} \mathrm{C}$ na estação chuvosa (Anuário Estatístico de Pernambuco, 1991).

Foram avaliados clones de palma-forrageira de um banco de germoplasma formado por 441 clones oriundos do Instituto Agronômico de Pernambuco. O estabelecimento dos clones foi feito no mês de maio de 2002 em área de $1.200 \mathrm{~m}^{2}$, utilizando-se artículos maduros, na posição inclinada, com espaçamento de 1,0 $\mathrm{m} \times 0,50 \mathrm{~m}$, de modo que cada clone foi distribuído em linhas, com quatro plantas por entrada. A adubação orgânica foi realizada com esterco bovino equivalente a $30.000 \mathrm{~kg} / \mathrm{ha}$, no momento do plantio e após cada corte. O primeiro corte do palmal foi realizado em 2005 para alimentação dos animais e o segundo no mês de julho de 2007, após a coleta de dados da primeira avaliação, deixando-se apenas os artículos primários nas plantas.

Avaliaram-se, ao acaso, 50 clones de palma (49 da espécie Opuntia ficus indica e um da espécie Nopalea cochenillifera), todos do programa de melhoramento genético do IPA (Tabela 1), em três avaliações (julho de 2007, fevereiro de 2008 e julho de 2008). Na primeira avaliação, mensuraram-se as características morfológicas das plantas e dos cladódios. Nas plantas avaliaram-se altura, largura, número de artículos, hábito de crescimento e presença de espinhos. As características analisadas nos cladódios, conforme a ordem e posição, foram largura, comprimento, perímetro, espessura, ângulo e presença de pelos. Na segunda e terceira avaliações, estudaram-se todas essas características mais o número e tamanho de espinhos.

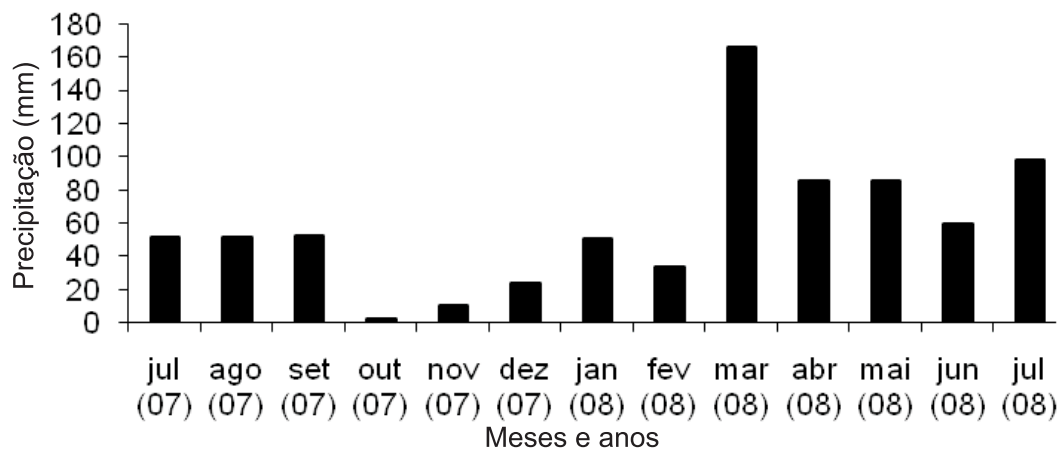

Figura 1 - Precipitação mensal durante o período experimental, Caruaru, Pernambuco. 
Tabela 1 - Clones avaliados no experimento no período de julho de 2007 a julho de 2008

\begin{tabular}{llllll}
\hline \multicolumn{7}{c}{ Clone avaliado } \\
\hline Clone 2 & Clone 285 & Clone 495 & Clone 773 & Clone 1042 \\
Clone 8 & Clone 313 & Clone 499 & Clone 782 & Clone 1043 \\
Clone 32 & Clone 315 & Clone 501 & Clone 796 & Clone 1080 \\
Clone 63 & Clone 334 & Clone 519 & Clone 801 & Clone 1098 \\
Clone 205 & Clone 394 & Clone 520 & Clone 823 & Clone 1107 \\
Clone 220 & Clone 397 & Clone 651 & Clone 841 & Clone 1153 \\
Clone 224 & Clone 404 & Clone 652 & Clone 852 & Clone 1234 \\
Clone 256 & Clone 406 & Clone 666 & Clone 916 & Clone 1235 \\
Clone 264 & Clone 418 & Clone 686 & Clone 993 & IPA-20 \\
Clone 274 & Clone 485 & Clone 725 & Clone 1031 & Miúda \\
\hline
\end{tabular}

Após a avaliação, realizou-se a colheita das plantas e de amostras de cladódios de diferentes ordens por clone, para determinação do teor de matéria seca.

$\mathrm{Na}$ medição da altura da planta, consideraram-se o comprimento (da extremidade do artículo mais alto até o solo) e a largura da planta na região de maior largura, ambos determinados com fita métrica. Foi realizada a contagem de artículos por ordem e atribuídas notas, por três avaliadores, para as características hábito de crescimento e presença de espinhos (Tabela 2).

Após as avaliações realizadas na planta, realizaram-se as medições dos artículos, independentemente da ordem. Nas medições de largura e comprimento dos artículos, foi utilizada fita métrica considerando a região de maior largura e comprimento do artículo. Posteriormente, foram feitas as medidas de perímetro, obtidas pelo contorno do artículo com fita métrica, e espessura dos artículos, utilizando-se paquímetro e medindo a região mais espessa.

As medidas de ângulo de inserção, formado entre o artículo emergente e seu artículo-base, foram obtidas com um transferidor. Em seguida, atribuíram-se notas, por três avaliadores, para a presença de pelos em cladódios (Tabela 2).

Tabela 2 - Notas atribuídas a clones de palma-forrageira para hábito de crescimento da planta, presença de pelos no cladódio e presença de espinhos na planta

\begin{tabular}{lc}
\hline Hábito de crescimento da planta & Nota \\
\hline Ereto & 1 \\
Semiaberto & 2 \\
Aberto & 3 \\
Presença de pelos em cladódios & \\
Ausência de pelo & 1 \\
Pouco pelo & 2 \\
Quantidade intermediária de pelo & 3 \\
Muito pelo & 4 \\
Presença de espinhos na planta & \\
Ausência de espinhos & 1 \\
Poucos espinhos & 2 \\
Quantidade intermediária de espinho & 3 \\
Muito espinho & 4 \\
\hline
\end{tabular}

Para a característica número de espinhos, utilizou-se um quadrado de papelão, com área total de $49 \mathrm{~cm}^{2}\left(7,0 \times 7,0 \mathrm{~cm}^{2}\right)$, que possui na sua região interna um corte na forma de quadrado, com dimensão de 5,0 $\times 5,0 \mathrm{~cm}^{2}$. Posteriormente, aproximou-se o quadrado de papelão na porção central de um artículo adulto (completamente desenvolvido) e em um artículo jovem (artículo em desenvolvimento), realizando a contagem dos espinhos presentes na área do quadrado de $5,0 \times 5,0 \mathrm{~cm}^{2}$. Após essa avaliação, cinco espinhos foram coletados da planta e, com o auxílio de uma régua, obtiveram-se as medidas de comprimento, em milímetros.

Após a coleta de dados da primeira avaliação, os clones foram colhidos aos dois anos de idade deixando apenas os artículos primários na planta. Após o corte, determinaram-se os pesos das plantas e coletaram-se artículos de diferentes ordens e clones para amostragem e determinação do teor de matéria seca. As amostras foram encaminhadas para o laboratório do Instituto Agronômico de Pernambuco, onde se obteve o peso dos artículos em balança de precisão. Os artículos foram cortados em fatias finas e pré-secos em estufa de ventilação forçada de ar, a $65^{\circ} \mathrm{C}$. A determinação de matéria seca foi realizada de acordo com metodologia proposta por Silva \& Queiroz (2002).

Foram realizadas estimativas de produção de matéria seca para a segunda e terceira avaliações, visto que, durante o período experimental, houve apenas um corte. Com base na produção de matéria seca ( $\mathrm{t} / \mathrm{ha} / 2$ anos) e nas médias de todas as características morfológicas obtidas na primeira avaliação, utilizou-se o programa computacional GENES (o aplicativo de regressão múltipla), que forneceu constante, $\mathrm{R}=0,99$ e coeficientes de regressão, permitindo utilização da equação de regressão múltipla no Excel descrita abaixo:

$\mathrm{Y}=\mathrm{A}+\mathrm{B} 1 * \mathrm{PMS}+\mathrm{B} 2 * \mathrm{AP}+\mathrm{B} 3 * \mathrm{LP}+\mathrm{B} 4 * \mathrm{NA} 1+$ $\mathrm{B} 5 * \mathrm{NA} 2+\mathrm{B} 6 * \mathrm{NA} 3+\mathrm{B} 7 * \mathrm{NA} 4+\mathrm{B} 8 * \mathrm{LA} 1+\mathrm{B} 9 * \mathrm{LA} 2$ $+\mathrm{B} 10 * \mathrm{LA} 3+\mathrm{B} 11 * \mathrm{LA} 4+\mathrm{B} 12 * \mathrm{PA} 1+\mathrm{B} 13 * \mathrm{PA} 2+\mathrm{B} 14 * \mathrm{PA} 3+$ $\mathrm{B} 15 * \mathrm{PA} 4+\mathrm{B} 16 * \mathrm{CA} 1+\mathrm{B} 17 * \mathrm{CA} 2+\mathrm{B} 18^{*} \mathrm{CA} 3+\mathrm{B} 19 * \mathrm{CA} 4+$ $\mathrm{B} 20 * \mathrm{HC}+\mathrm{B} 21 * \mathrm{PPE}+\mathrm{B} 22 * \mathrm{PE}+\mathrm{B} 23 * \mathrm{NEAJ}+\mathrm{B} 24 * \mathrm{NEAA}$ $+\mathrm{B} 25 * \mathrm{CE}$

As seguintes características morfológicas foram utilizadas na fórmula para estimativa da produção de matéria seca da segunda avaliação: produção de matéria seca da primeira avaliação (PMS t/ha/2anos); altura da planta (AP); largura da planta (LP); número de artículos de primeira, segunda, terceira e quarta ordem (NA1, NA2, NA3 e NA4); largura de artículos primeira, segunda, terceira e quarta ordem (LA1, LA2, LA3 e LA4); perímetro de artículos primeira, segunda, terceira e quarta ordem (PA1, PA2, PA3 e PA4), comprimento de artículos primeira, segunda, terceira e quarta ordem (CA1, CA2, CA3 e CA4); hábito de 
crescimento (HC); presença de pelos (PPE); presença de espinhos (PE); número de espinhos em artículos jovens e adultos (NEAJ e NEAA) e comprimento de espinhos (CE).

Em seguida, os dados experimentais foram analisados por meio de estatística descritiva, obtendo-se média, mínimo, máximo e coeficiente de variação $(\mathrm{CV})$ analisados pelo programa GENES, conforme metodologia de Cruzetal. (2004). Todas as características citadas e descritas anteriormente passaram por um teste de multicolinearidade, com auxílio do programa GENES. Aquelas características que apresentaram magnitude fraca foram utilizadas para realização da correlação fenotípica de Pearson e análise de trilha.

As correlações entre as variáveis fenotípicas estudadas foram obtidas considerando 50 parcelas isoladamente, por meio do coeficiente de correlação de Pearson, utilizando-se o programa GENES, pela metodologia de Cruz et al. (2004).

Para o estudo do efeito das variáveis na análise de trilha, considerou-se como variável-dependente principal a produção de matéria seca em (t/ha/2 anos). Como variáveisindependentes explicativas, foram utilizadas as seguintes variáveis: altura média das plantas (AP), largura média da planta (LP), largura do artículo primário (LA1), largura do artículo secundário (LA2), comprimento do artículo primário (CA1), comprimento do artículo secundário (CA2) e espessura do artículo terciário (EA3). Utilizou-se a metodologia descrita por Cruz \& Regazzi (1997), em que os coeficientes de trilha foram obtidos pela equação: $\mathrm{Y}=\mathrm{P}_{01} \mathrm{X}_{1}$ $+\mathrm{P}_{02} \mathrm{X}_{2}+\ldots+\mathrm{P}_{0 \mathrm{n}} \mathrm{X}_{\mathrm{n}}+\mathrm{P} \varepsilon \mu$, em que $\mathrm{Y}=$ coeficiente da variável-dependente; $\mathrm{P}_{0}=$ coeficiente de efeito direto; $\mathrm{X}=$ variável-dependente explicativa; $\mathrm{P} \varepsilon=$ efeito residual; $\mathrm{e}$ $\mu=$ variável de padronização.

\section{Resultados e Discussão}

A produção média de matéria seca foi de $7,1 \mathrm{t} / \mathrm{ha} / 2$ anos, considerando a produção dos cladódios primários (Tabela 3), valor superior ao obtido por Menezes et al. (2005), que analisaram 50 propriedades rurais nos estados de Pernambuco e Paraíba e observaram produtividade média da palma-forrageira de 5,7 t/ha/2anos, com os cladódios primários preservados no primeiro corte e $7,2 \mathrm{t} / \mathrm{ha} / 2$ anos, com toda a biomassa produzida pela palma, incluindo os cladódios primários.

Os clones mais produtivos foram 8,782 e 418 ; e o menos produtivos 841,1107 e 501 com produção de matéria seca de 40,$8 ; 18,1 ; 12,1 ; 2,2 ; 1,4 \mathrm{e} 1,3 \mathrm{t} / \mathrm{ha} / 2$ anos, respectivamente. A produtividade média obtida neste trabalho $(7,1 \mathrm{t} / \mathrm{ha} / 2 \mathrm{anos})$ é compatível com o crescimento da planta sob condições de pouca disponibilidade de água. Sampaio (2005) comenta que o processo fotossintético MAC, caracterizado pela

Tabela 3 - Estatística descritiva para produtividade e características morfológicas de clones de palma-forrageira (médias de três avaliações)

\begin{tabular}{|c|c|c|c|c|}
\hline Variável & Média & Mínimo & Máximo & $\mathrm{CV}(\%)$ \\
\hline Produção de matéria seca (t MS/ha/2anos) & 7,1 & 1,3 & 40,8 & 82,7 \\
\hline Altura da planta $(\mathrm{cm})$ & 90,1 & 45,2 & 127,3 & 17,8 \\
\hline Largura da planta $(\mathrm{cm})$ & 71,5 & 19,0 & 116,0 & 30,6 \\
\hline Número de artículos primários & 2,8 & 1,0 & 7,0 & 47,7 \\
\hline Número de artículos secundários & 6,8 & 1,3 & 11,3 & 37,6 \\
\hline Número de artículos terciários & 2,9 & 1,0 & 12,7 & 76,5 \\
\hline Ângulo de artículos primários & 44,0 & 7,5 & 90,0 & 48,5 \\
\hline Ângulo de artículos secundários & 26,2 & 10,8 & 94,3 & 48,2 \\
\hline Ângulo de artículos terciários & 12,2 & 5,0 & 40,9 & 83,7 \\
\hline Perímetro de artículos primários $(\mathrm{cm})$ & 68,3 & 31,7 & 95,0 & 20,60 \\
\hline Perímetro de artículos secundários $(\mathrm{cm})$ & 50,5 & 23,5 & 68,0 & 13,3 \\
\hline Perímetro de artículos terciários $(\mathrm{cm})$ & 37,7 & 20,5 & 70,3 & 39,9 \\
\hline Largura dos artículos primários $(\mathrm{cm})$ & 16,5 & 8,8 & 24,0 & 23,6 \\
\hline Largura dos artículos secundários $(\mathrm{cm})$ & 11,0 & 7,6 & 21,7 & 16,9 \\
\hline Largura dos artículos terciários $(\mathrm{cm})$ & 9,6 & 4,8 & 21,0 & 42,2 \\
\hline Comprimento dos artículos primário $(\mathrm{cm})$ & 28,1 & 10,3 & 40,0 & 21,8 \\
\hline Comprimento dos artículos secundários $(\mathrm{cm})$ & 22,0 & 10,3 & 30,0 & 13,7 \\
\hline Comprimento dos artículos terciário $(\mathrm{cm})$ & 15,8 & 4,8 & 29,6 & 40,9 \\
\hline Espessura dos artículos primários $(\mathrm{cm})$ & 3,9 & 2,3 & 6,7 & 21,7 \\
\hline Espessura dos artículos secundários $(\mathrm{cm})$ & 1,8 & 1,3 & 2,5 & 12,0 \\
\hline Espessura dos artículos terciários $(\mathrm{cm})$ & 1,2 & 0,6 & 2,2 & 35,0 \\
\hline Hábito de crescimento da planta ${ }^{1}$ & 1,7 & 1,2 & 1,9 & 6,1 \\
\hline Presença de pelos ${ }^{1}$ & 1,8 & 1,2 & 2,1 & 6,2 \\
\hline Presença de espinhos ${ }^{1}$ & 2,0 & 1,2 & 2,1 & 7,3 \\
\hline Número de espinhos em artículos jovens & 4,2 & 1,0 & 9,0 & 49,1 \\
\hline Número de espinhos em artículos adultos & 3,5 & 1,0 & 9,0 & 53,0 \\
\hline Comprimento de espinhos $(\mathrm{mm})$ & 8,5 & 3,9 & 13,8 & 31,3 \\
\hline
\end{tabular}

${ }^{1}$ Nota variando de 1 a 3 para hábito de crescimento e de 1 a 4 para presença de pelos e de espinhos. 
fixação de $\mathrm{CO}_{2}$ durante a noite, é um mecanismo eficiente de adaptação ao crescimento em condições de baixa disponibilidade de água.

Apesar de o palmal ter sido adubado com esterco bovino, a produtividade média foi baixa, o que não concorda com a afirmativa de Dubeux Jr. \& Santos (2005) de que a utilização de esterco bovino eleva a produtividade do palmal, principalmente quando aplicado juntamente com fertilizantes químicos.

O coeficiente de variação observado para a produção de matéria seca foi alto $(82,7 \%)$, indicando que houve grande variação na produção entre os diferentes clones. Araújo Filho et al. (2007), trabalhando com palma-forrageira, também observaram que há diferença em termos de produção entre os clones estudados, permitindo a seleção de clones mais produtivos.

Entre os clones avaliados no palmal, o clone 8, oriundo do programa de melhoramento genético do IPA, destacou-se por apresentar produção de 40,8 t/ha/2anos, $127,3 \mathrm{~cm}$ de altura; $113,6 \mathrm{~cm}$ largura, 11 artículos secundários, 13 artículos terciários, perímetro médio de artículos primários, secundários e terciários de 82,50 e $41 \mathrm{~cm}$, largura média de artículos primários, secundários e terciários equivalentes a 24; 10,5 e $10 \mathrm{~cm}$, espessura média de artículos primários, secundários e terciários de 6,$75 ; 2,03$ e 1,63 cm, com poucos pelos e espinhos, cujo tamanho médio foi de $0,75 \mathrm{~mm}$. Estas características encorajam o cultivo do clone 8 para uso na alimentação animal em períodos críticos.

Os clones avaliados apresentaram altura e largura média de planta de aproximadamente 90,1 e $71,5 \mathrm{~cm}$, respectivamente, sendo o CV para altura de $17,8 \%$ e para largura de 30,6\%. Assim, embora essas características sejam influenciadas pela genética dos clones estudados, pelo hábito de crescimento da planta, pelo ângulo de inserção entre os eixos longitudinais do artículo emergente e seu artículo-base, a variação dessas características entre os clones foi menor que a variação da produção.

Ferreira et al. (2003), trabalhando com características morfológicas de palma-forrageira, observaram altura máxima e mínima da planta de 122,9 e 70,2 cm em clones colhidos com 2 anos de idade. Martins et al. (1999), em trabalho sobre densidade de plantio, concluíram que, quanto maior a densidade de plantas, maior a altura final das mesmas, por haver redução do alongamento lateral do caule, devido à competição entre plantas. Conforme Knebel et al. (2006), o arranjo das plantas pode ser modificado pela variação na população de plantas e pelo espaçamento entre linhas, alterando a área e a forma da área disponível para cada planta.
O número de artículos variou conforme a ordem e o clone, com coeficientes de variação altos para as três ordens. O maior valor foi obtido para os artículos secundários, uma vez que a planta apresenta vários artículos primários, que são responsáveis pela emissão de novos artículos (artículo secundário), enquanto os artículos primários são originados apenas de uma única raquete, denominada raquete-mãe. Os artículos terciários foram entrados em menor quantidade, possivelmente em razão do maior sombreamento dos artículos secundários.

De maneira geral, Flores-Flores \& Tekelenburg (2001) ressaltaram que as temperaturas altas atrasam o surgimento de brotações dos artículos e que o tempo de duração das chuvas pode induzir os ciclos de surgimento de novos artículos. Finalmente, os coeficientes de variação altos estão relacionados às diferenças entre os clones estudados, que apresentam genética distinta e respondem à variação na fertilidade do solo, influenciando a quantidade de artículos por ordem.

Os cladódios primários apresentaram maior ângulo de inserção com o artículo-base, característica determinada pela genética da planta. Observaram-se também altos coeficientes de variação para os ângulos de artículos, o que pode ter sido ocasionado pela variação entre os avaliadores no momento da coleta dos dados no campo, visto que, na primeira avaliação, o palmal estava com difícil acesso, o que tornou necessário o revezamento entre avaliadores.

As maiores medidas de perímetro, largura, comprimento e espessura foram obtidas nos cladódios primários e reduziram com a emissão de novas ordens de artículos. Essas maiores medidas obtidas nos artículos primários são resultantes de sua idade, já que os artículos primários são mais velhos e têm como função a sustentação dos demais artículos, das flores e dos frutos, bem como o transporte de nutrientes e substâncias orgânicas necessárias para a subsistência da planta.

As características número, ângulo, perímetro, largura, comprimento e espessura de artículos terciários apresentaram coeficientes de variação muito altos se comparados aos coeficientes de variação das ordens. Isso provavelmente ocorreu porque alguns artículos terciários estavam expandidos e outros em expansão, o que resultou em diferenças nos resultados.

O hábito de crescimento dos clones estudados variou de ereto a semiaberto, com predominância do hábito semiaberto. O estudo dessa característica morfológica tem grande importância, pois influencia indiretamente na interceptação da radiação pelas plantas, determinada pela arquitetura da planta. Santos et al. (2007) estudaram 
características morfológicas de palma-forrageira e observaram que a atribuição de notas foi eficiente na caracterização do hábito de crescimento dos clones.

Foi observada a presença de poucos pelos nos cladódios das plantas avaliadas (Tabela 3). Hills (2001) relata que os pêlos espinhosos são originados de uma túnica e corpus como o primórdio foliar e que sua quantidade e duração depende das espécies que pertencem ao subgênero Opuntia.

Verificaram-se poucos espinhos nas plantas, com média nos seus artículos jovens e adultos de 4,2 e 3,5 espinhos a cada $5 \mathrm{~cm}^{2}$, respectivamente, característica determinada pela genética da planta. No entanto, neste trabalho não houve a preocupação de retirar os acúleos que estavam presentes dentro do corte realizado no quadrado de papelão no momento da contagem, portanto foram contados juntamente com os espinhos. Assim, os artículos adultos apresentaram-se em menor número porque as condições ambientais e o pleno desenvolvimento dos artículos promoveram a queda dos acúleos, ficando apenas os espinhos. Outro fator que pode ter contribuído para o menor numero de espinhos nos clones estudados foi que os 50 clones plantados em Caruaru foram resultantes de seleção prévia na qual foram eliminados aqueles mais agressivos.

Conforme reportado por Robinson (1974), a maioria dos acúleos está presente no primeiro estágio de crescimento dos artículos e cai com o aumento da temperatura, permanecendo apenas espinhos nos cladódios. A média do tamanho de espinhos foi de $8,5 \mathrm{~mm}$, valor inferior ao obtido por Hills (2001), que, estudando palma-forrageira, observou tamanho de espinhos variando de 10 a $15 \mathrm{~mm}$ de comprimento, provavelmente por essa característica ser determinada pela genética da planta.

Todas as variáveis tiveram correlação positiva com a produção de matéria seca, mas essas correlações foram significativas apenas para a altura da planta, largura da planta, largura do artículo primário e comprimento do artículo primário, logo clones mais produtivos apresentam maior altura e largura, além de artículos primários mais largos e compridos (Tabela 4). Conforme relatos de Cruz \& Regazzi (1997), a existência de correlações significativas indica a viabilidade da seleção indireta para a obtenção de ganhos na característica de maior importância econômica.

Para as variáveis largura do artículo secundário, comprimento do artículo secundário e espessura do artículo terciário, os coeficientes de correlação de Pearson foram positivos, porém baixos e não-significativos, com a produção de matéria seca. $\mathrm{O}$ fato de essas variáveis apresentarem baixa correlação não implica que não estejam associadas entre si. Vencovsky \& Barriga (1992) relataram que há associação entre características, mesmo com baixas magnitudes.

Verificou-se pela correlação de Pearson que a altura da planta apresentou maior magnitude de associação com a produção de matéria seca. Todavia, os coeficientes de correlação para a variável altura de planta indicam que as plantas mais altas possuem maior largura de planta, artículos primários largos e compridos, artículos secundários compridos e artículos terciários espessos.

Observou-se, também pela correlação fenotípica de Pearson, que as plantas mais largas tendiam a apresentar artículos primários largos e compridos. A largura do artículo primário comprovou alta correlação positiva e significativa com o comprimento do artículo primário $(\mathrm{r}=0,74)$, desse modo, pode-se concluir que ocorre um sistema de interrelações entre as características associadas.

Coimbra et al. (2005), em trabalho com análise de trilha, verificaram que, quanto maior o grau de multicolinearidade, maiores as estimativas dos coeficientes de correlação e menor a precisão em sua estimativa, sendo necessária a realização antecipada da análise de multicolinearidade. Entretanto, tendo como critério básico a análise prévia de multicolinearidade dos dados e observados os descritores

Tabela 4 - Coeficientes de correlação fenotípica de Pearson entre as características morfológicas de clones de palma-forrageira determinados com base na média de três avaliações

\begin{tabular}{|c|c|c|c|c|c|c|c|}
\hline Variável & $\begin{array}{l}\text { Produção de } \\
\text { matéria seca } \\
(\mathrm{t} / \mathrm{ha} / 2 \text { anos })\end{array}$ & $\begin{array}{c}\text { Altura } \\
\text { da planta } \\
(\mathrm{cm})\end{array}$ & $\begin{array}{c}\text { Largura } \\
\text { da planta } \\
(\mathrm{cm})\end{array}$ & $\begin{array}{l}\text { Largura } \\
\text { do artículo } \\
\text { primário } \\
\text { (cm) }\end{array}$ & $\begin{array}{c}\text { Largura } \\
\text { do artículo } \\
\text { secundário } \\
(\mathrm{cm})\end{array}$ & $\begin{array}{l}\text { Comprimento } \\
\text { do artículo } \\
\text { primário } \\
(\mathrm{cm})\end{array}$ & $\begin{array}{c}\text { Comprimento } \\
\text { do artículo } \\
\text { secundário } \\
(\mathrm{cm})\end{array}$ \\
\hline Altura da planta $(\mathrm{cm})$ & $0,61 * *$ & - & & & & & \\
\hline Largura da planta $(\mathrm{cm})$ & $0,56 * *$ & $0,58 * *$ & - & & & & \\
\hline Largura do artículo primário (cm) & $0,44 * *$ & $0,37 * *$ & $0,33 *$ & - & & & \\
\hline Largura do artículo secundário $(\mathrm{cm})$ & 0,02 & 0,22 & 0,23 & 0,03 & - & & \\
\hline Comprimento do artículo primário $(\mathrm{cm})$ & $0,39 * *$ & $0,37 * *$ & $0,34 *$ & $0,74 * *$ & $-0,06$ & - & \\
\hline Comprimento do artículo secundário $(\mathrm{cm})$ & 0,21 & $0,43 * *$ & 0,26 & $0,31 *$ & $-0,13$ & 0,14 & - \\
\hline Espessura do artículo terciário $(\mathrm{cm})$ & 0,22 & $0,33 *$ & 0,19 & 0,06 & 0,02 & 0,11 & 0,15 \\
\hline
\end{tabular}

**,*Significativo a 1 e $5 \%$ de probabilidade, pelo teste $\mathrm{t}$ 
de colinearidade fraca, fez-se o desdobramento das correlações fenotípicas em efeito direto e indireto dos caracteres dos clones de palma-forrageira (Tabela 5).

De maneira geral, os resultados indicam que as sete características estudadas diferiram quanto ao seu grau de

Tabela 5 - Desdobramento das correlações fenotípicas de características da palma-forrageira em efeitos diretos e indiretos sobre a produção de matéria seca (t/ha/2anos) pela análise de trilha

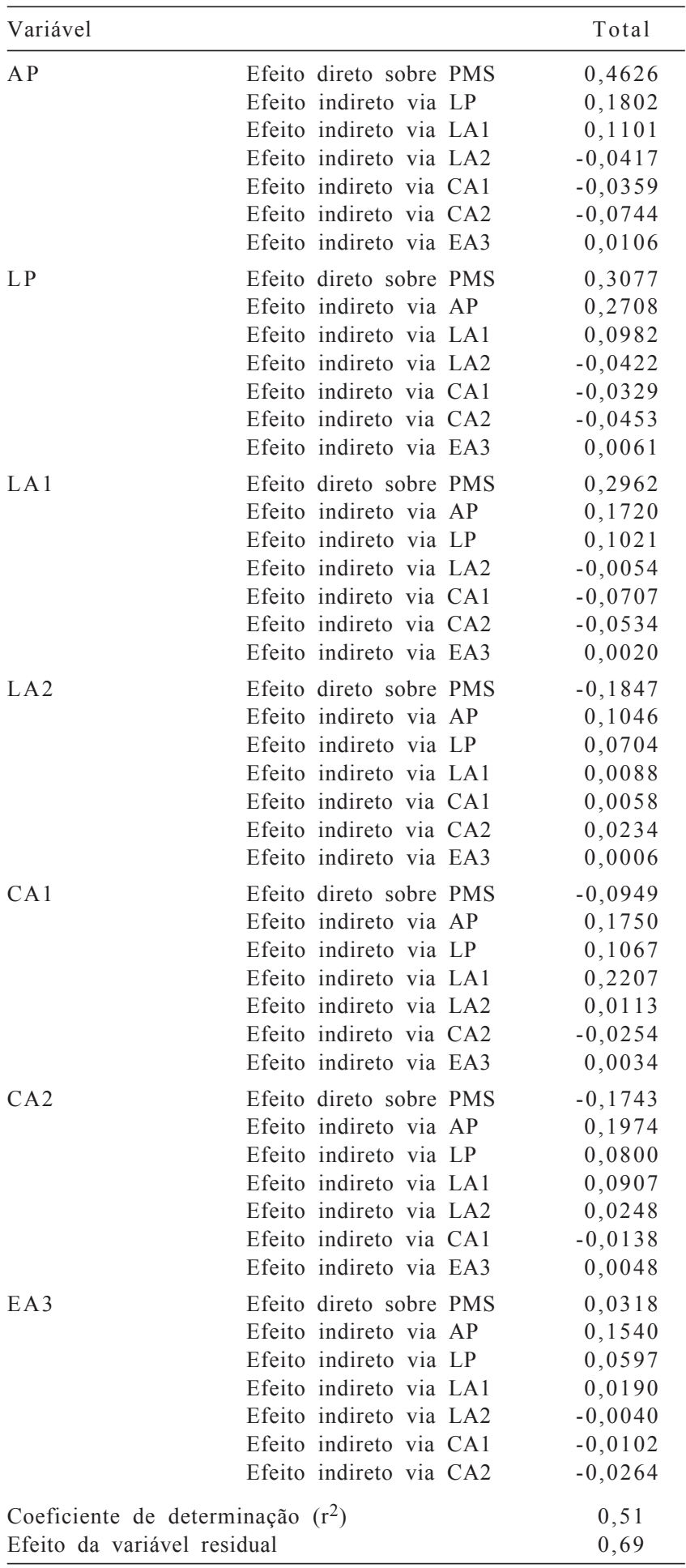

influência direta sobre a produção de matéria seca. Todas as variáveis estudadas tiveram efeito direto em pelo menos $51 \%$ da produção de matéria seca, com magnitude inferior à de correlação de Pearson para cada variável analisada, o que comprova a existência de outras características influenciando, tanto em magnitude, como no sentido da correlação (Tabela 5).

Dessa forma, torna-se difícil a seleção isolada de uma variável visando à produção de matéria seca. Assim, a altura da planta (maior correlação linear com a produção) deve ser utilizada em associação a outras variáveis, entretanto, seus efeitos indiretos podem ser utilizados para auxiliar no aumento da correlação por outra característica. Caierão et al. (2001) relataram que, na análise de trilha, pode haver variáveis em que o efeito direto das característica estudadas é menor que a correlação de Pearson, o que dificulta a seleção de apenas uma variável visando ganhos na característica desejada.

As características largura da planta e largura do artículo primário apresentaram correlação moderada com a produção de matéria seca, porém essa correlação se deve muito pouco ao seu efeito direto: é influenciada pelos efeitos indiretos, principalmente pela altura da planta. O baixo efeito da largura da planta pode ser explicado pelo fato de essa característica ser resultante de uma sequência de artículos em diferentes estágios de crescimento, o que justifica a influência indireta da altura da planta.

Apesar da correlação significativa do comprimento do artículo primário com a produção de matéria seca, seu efeito direto foi de magnitude baixa e a produção foi determinada pelo efeito indireto da altura da planta. Neste contexto, os artículos primários são responsáveis por sustentar os demais, assim é uma característica influenciada indiretamente pela altura da planta.

Sales et al. (2003) comentam que, além da genética da planta, as oscilações climáticas influenciam na largura e no comprimento dos artículos, afetando, desse modo, a produção.

A largura e o comprimento do artículo secundário e a espessura do artículo terciário também apresentaram baixo coeficiente de correlação com a produção de matéria seca. Neste caso, a correlação é promovida pelos efeitos indiretos e os fatores casuais indiretos devem ser considerados simultaneamente no processo de seleção. De acordo com Montardo et al. (2003), um dos motivos da baixa correlação entre variáveis seria a pouca variabilidade em uma dessas variáveis, já que a análise de trilha identifica uma eventual associação na variação das características em estudo.

A decomposição dos efeitos das variáveis analisadas sobre a produção de matéria seca apontou a altura da planta como a característica morfológica mais indicada para a seleção 
indireta, principalmente por apresentar maior correlação fenotípica de Pearson e efeito direto (Tabela 5), porém, apesar de ter apresentado maior efeito direto, sua magnitude é baixa, por isso, é recomendável a associação de características.

$\mathrm{O}$ coeficiente de determinação geral $\left(\mathrm{r}^{2}\right)$ tendeu a aumentar com a associação das variáveis, fato explicado pela maior correlação com a produção de matéria seca $(0,71)$. Os efeitos diretos das características altura e largura da planta podem ser considerados no processo de seleção indireta por apresentar magnitude alta (Tabela 6). As características largura do artículo primário e espessura do artículo terciário indicam que os efeitos indiretos das características associadas superaram os efeitos diretos, logo a altura e largura da planta são o principal determinante das variações na produção, reforçando que a seleção baseada na altura da planta associada à largura da planta é eficiente para aumentar a produção.

A largura do artículo secundário e o comprimento do artículo secundário apresentaram baixos coeficientes de correlação fenotípica com a produção de matéria seca, porém, o efeito indireto das características associadas (altura da planta vs. largura da planta) deve ser considerado no processo de seleção de clones de palma-forrageira por apresentar maior efeito indireto.

O baixo efeito direto da largura do artículo secundário e do comprimento do artículo secundário na produção de matéria seca pode ser explicado pelo fato de que essas características fazem parte da arquitetura da planta, justificando a influência indireta da altura da planta associada à largura da planta (altura da planta $\times$ largura da planta).

Pessoa (1967) comenta que as raquetes secundárias são importantes na formação da futura planta, pois constituem o futuro esqueleto do vegetal, o seu "tronco", seu arcabouço, a parte que será preservada nos futuros cortes, refletindo diretamente a precocidade e a produção da planta a se formar.

O comprimento do artículo primário apresentou correlação fenotípica moderada e positiva, porém de efeito direto negativo, ou seja, causada pelos efeitos indiretos.
Tabela 6 - Desdobramento das correlações fenotípicas de características da palma forrageira em efeitos diretos e indiretos sobre a produção de matéria seca $(\mathrm{t} / \mathrm{ha} / 2 \mathrm{anos})$ pela análise de trilha

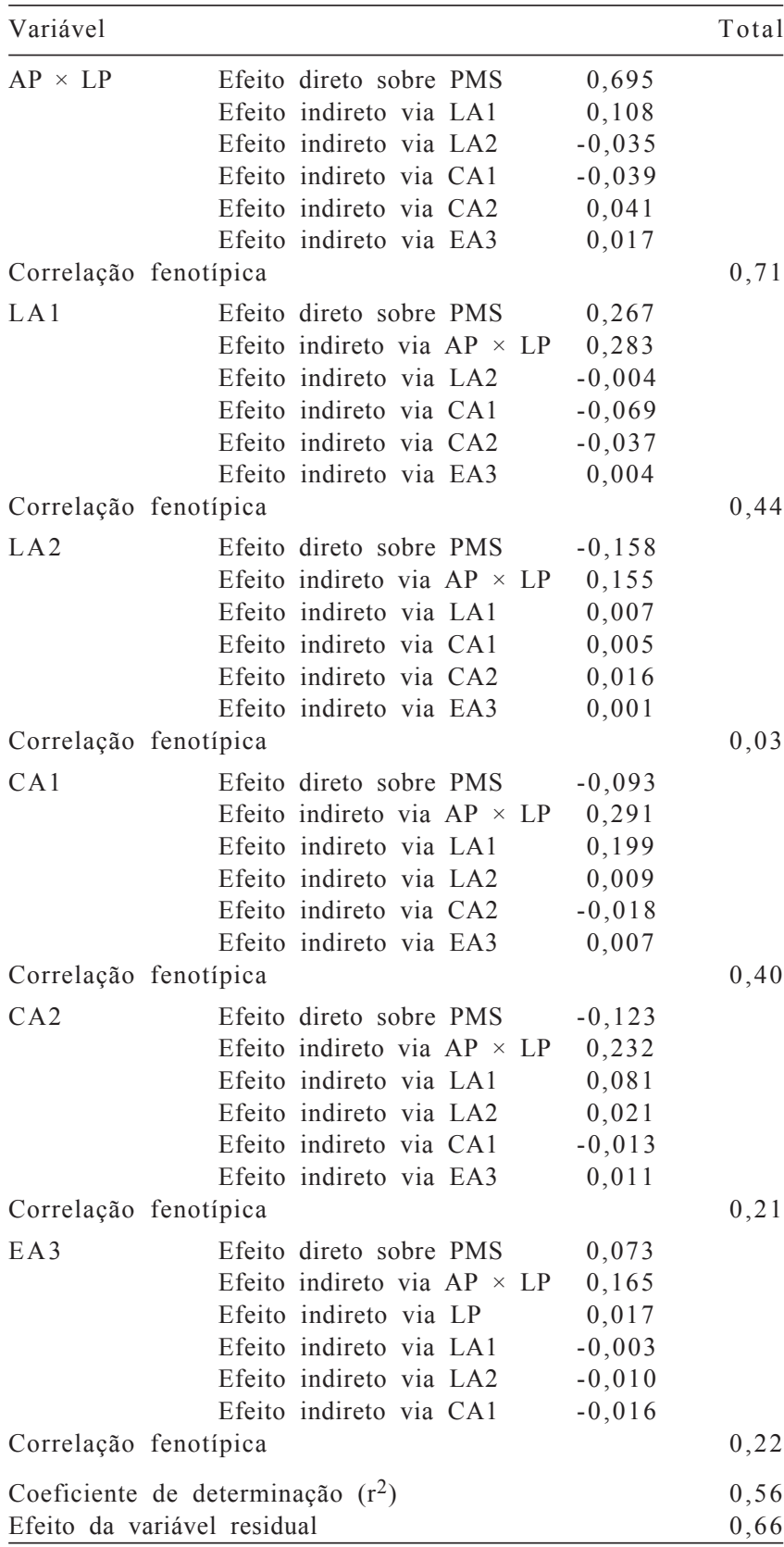

PMS - produção de matéria seca (t de MS/ha/2ano); AP - altura da planta $(\mathrm{cm})$; LP - largura da planta $(\mathrm{cm}) ; \mathrm{LA} 1$ - largura do artículo primário $(\mathrm{cm}) ; \mathrm{LA} 2-$ comprimento do artículo secundário $(\mathrm{cm})$; CA1 - comprimento do artículo primário $(\mathrm{cm}) ; \mathrm{CA} 2$ - comprimento do artículo secundário $(\mathrm{cm})$; EA3 - espessura do artículo terciário $(\mathrm{cm})$. 
Vencovsky \& Barriga (1992) reforçam que, nesses casos, os fatores casuais indiretos devem ser considerados simultaneamente no processo de seleção, uma vez que o efeito direto negativo indica ausência de causa e efeito, ou seja, que essa característica não é a principal determinante das alterações na variável básica e que existem outras que poderão proporcionar maior ganho de seleção.

\section{Conclusões}

Em programas de melhoramento de palma-forrageira visando acréscimo na produção de matéria seca em toneladas por hectare a cada dois anos, deve-se priorizar a seleção de clones de maior altura e largura da planta.

\section{Referências}

ANUÁRIO ESTATÍSTICO DE PERNAMBUCO. Recife: IBGE, 1991. v.40. $1024 \mathrm{p}$

ARAUJO FILHO, J.T.; SILVA, F.G.; OLIVEIRA, J.C. et al. Production of dry matter in varieties of Opuntia in the semiarid zone of Alagoas, Brasil. In: CONGRESSO INTERNACIONAL DE PALMA, 6., 2007, João Pessoa. Anais... João Pessoa: 2007. (CD-ROM).

BISPO, S.V.; FERREIRA, M.A.; VÉRAS, A.S.C. et al. Palma forrageira em substituição ao feno de capim-elefante. Efeito sobre consumo, digestibilidade e características de fermentação ruminal em ovinos. Revista Brasileira de Zootecnia, v.36, n.6, p.1902-1909, 2007.

CAIERAO, E.; CARVALHO, F.I.F.; PACHECO, M.T. et al. Seleção indireta em aveia para o incremento no rendimento de grãos. Ciência Rural, v.31, n.2, p.231-236, 2001.

COIMBRA, J.L.M. Divergência genética em feijão preto. Ciência Rural, v.29, n.3, p.427-431, 1999

COIMBRA, J.L.M.; BENIN, G.; VIEIRA, E.A. et al. Conseqüência de multicolinearidade sobre a análise de trilha em canola. Ciência Rural, v.35, n.2, p.348-356, 2005.

CRUZ, C.D.; CARNEIRO, P.C.S. Modelos biométricos aplicado a melhoramento genético. 2.ed. Viçosa, MG: Editora universitária da UFV, 2003. v.2, p.348-356.

CRUZ, C.D.; REGAZZI, A.J. Modelos biométricos aplicados ao melhoramento genético e estatístico. Viçosa, MG: Editora UFV, 1997. 393p.

CRUZ, C.D.; REGAZZI, A.J.; CARNEIRO, P.C.S. Modelos biométricos aplicado ao melhoramento genético. 3.ed. Viçosa, MG: Editora universitária da UFV, 2004. v.1, p.180-192.

DUBEUX JR, J.C.B.; SANTOS, M.V.F. Exigências nutricionais da palma forrageira. In: MENEZES, R.S.C.; SIMÕES, D.A.; SAMPAIO, E.V.S.B. (Eds.) A palma no Nordeste do Brasil: conhecimento atual e novas perspectivas de uso. Recife: UFPE, 2005. p.105-127.

FALCONER, D.S. Introdução à genética quantitativa. Viçosa, MG: UFV, 1987. 279p

FERREIRA, C.A.; FERREIRA, R.L.C.; SANTOS, D.C. et al Utilização de técnicas multivariadas na avaliação da divergência genética entre clones de palma forrageira (Opuntia fícus indica Mill). Revista Brasileira de Zootecnia, v.32, n.6, p.1560-1568, 2003

FLORES-FLORES, V.; TEKELENBURG, A. Produção de corante dacti (Dactylopius coccus Costa). In: INGLESE, G.B.P.; BARRIOS, E.P. (Eds). Agroecologia cultivo e usos da palma forrageira. 2.ed. Paraíba: SEBRAE, 2001. p.169-186.

HILLS, F.S. Anatomia e morfologia. In: INGLESE, G.B.P.; BARRIOS, E.P. (Eds). Agroecologia cultivo e usos da palma forrageira. 2.ed. Paraíba: SEBRAE, 2001. p.28-35.

KNEBEL, J.L.; GUIMARÃES, V.F.; ANDREOTTI, M. et al. Influência do espaçamento e população de plantas sobre doenças de final de ciclo e oídio e caracteres agronômicos em soja. Acta Scientia Agronomica, v.28, n.3, p.385-392, 2006.

MARTINS, M.C.; SAMPAIO, J.C.; RIBEIRO, A.G. et al. Épocas de semeadura, densidades de plantas e desempenho vegetativo de cultivares de soja. Scentia Agricola, v.56, n.4, p.851858,1999 .

MENEZES, R.S.C.; SAMPAIO, E.V.S.B.; SALCEDO, I.H. et al. Produtividade de palma forrageira em propriedades rurais. In: MENEZES, R.S.C.; SIMÕES, D.A.; SAMPAIO, E.V.S.B. (Eds). A palma no Nordeste do Brasil conhecimento atual e novas perspectivas de uso. 2.ed. Recife: Editora Universitária da UFPE, 2005. p.129-141.

MONTARDO, D.P.; AGNOL, M.D.; CRUSIUS, A.F. et al. Analise de trilha para rendimento de sementes de trevo vermelho (Trifolium pratense L.). Revista Brasileira de Zootecnia, v.32, n.5, p.1076-1082, 2003.

PESSOA, A.S. Cultura da palma forrageira. Recife: 1967. 99p.

ROBINSON, H. Scanning electron microscope studies of the spines and glochids of the opuntioides (cactaceae). Journal of Botanic, v.61, n.3, p.278-283, 1974.

SALES, A.T.; ANDRADE, A.P.; SILVA, D.S. et al. Taxa de crescimento relativo de palma forrageira (Nopalea cochenillifera Salm-Dyck). Pesquisa Agropecuária Brasileira, v.34, n.1, p.340-346, 2003.

SAMPAIO, E.V.S.B. Fisiologia da palma. In: MENEZES, R.S.C.; SIMÕES, D.A.; SAMPAIO, E.V.S.B. (Eds). A palma no Nordeste do Brasil conhecimento atual e novas perspectivas de uso. 2.ed. Recife: Editora universitária da UFPE, 2005. p.43-63.

SANTOS, G.R.A.; CUNHA, M.V.; SANTOS, D.C. et al. Yield components in forage cactus pear genotypes in sertão of Pernambuco, Brazil. In: CONGRESSO INTERNACIONAL DE PALMA, 6., 2007, João Pessoa. Anais... João Pessoa: 2007. (CD-ROM).

SILVA, D.J.; QUEIROZ, A.C. Análise de alimentos: métodos químicos e biológicos. 3.ed. Viçosa, MG: UFV, Imprensa Universitária, 2002. 235p.

VENCOVSKY, R.; BARRIGA, P. Genética biométrica no fitomelhoramento. Revista Brasileira de Genética, v.15, n.4, p.496, 1992 . 